\title{
Status of Soil-Transmitted Helminths Infection in Ethiopia
}

\author{
Fikresilasie Samuel \\ Department of Medicine, Ambo University, Ambo, Ethiopia
}

Email address:

fikre16sam@gmail.com

To cite this article:

Fikresilasie Samuel Tasew. Status of Soil-Transmitted Helminth Infection in Ethiopia. American Journal of Health Research. Vol. 3, No. 3, 2015, pp. 170-176. doi: 10.11648/j.ajhr.20150303.21

\begin{abstract}
Soil-transmitted helminth infections are among the most common infections worldwide and affect the poorest and most deprived communities. The three major soil-transmitted helminths (STHs), i.e., Ascaris lumbricoides, Trichuris trichiura and Necator americanus/Ancylostoma duodenale are among the most widespread parasites worldwide. It is estimated that more than 880 million children are in need of treatment for these parasites globally. Several studies in Ethiopia also revealed that intestinal parasite infections are widely distributed with high prevalence rates. This paper reviews status of soil-transmitted helminths prevalence, their impact on health and measurement now taken to monitor the infection in Ethiopia context.
\end{abstract}

Keywords: Soil-Transmitted Helminth, Parasite, Ascaris lumbricoides, Trichuris trichiura, Hookworm

\section{Introduction}

STH infections are among the most prevalent and widespread chronic human infections worldwide (Stoll, 1999). The most common STHs which is found worldwide are: Ascaris lumbricoides, Trichuris trichiura and the hookworms, (Necator americanus and Ancylostoma duodenale), with an estimated 5.3 billion people worldwide, including 1.0 billion school aged children, living in areas of stable transmission for at least one STH species (Pullan and Brooker, 2012), with the greatest public health burden occurring in developing countries, particularly in subSaharan Africa (Bethony et al. 2006). The majority of these infections result from low standard of living, poor socioeconomic status, poor personal hygiene, and poor environmental sanitation (Bundy and Gutatt, 1996). STH infections are widely distributed in tropical and sub-tropical areas, especially in poor populations.

For all human STHs studied to date, which so far includes Ascaris, Trichuris, both hookworms, and Enterobius worm burdens exhibit a highly over-dispersed distribution so that most individuals harbor just a few worms in their intestines while a few hosts harbor disproportionately large worm burdens (Bundy, 1995). These heavily infected individuals are simultaneously at highest risk of disease and the major source is environmental contamination (Bundy, 1995). In the case of Ascaris and Trichuris infections, over-dispersed distributions also exhibit age dependency, with a peak in the childhoods, but with a subsequent decline among adults
(Bundy, 1995).

The highest prevalence and intensity of infection are usually observed in school-aged children (WHO, 2003). Numerous studies covering a diversity of geographic regions worldwide also indicate that for Ascaris and Trichuris infections maximum worm burdens occur in human populations at 5-10 years of age (Bundy, 1995). Although heavy hookworm infections occur in childhood, frequency and intensity commonly remain high in adulthood, even in elderly people (Bethony et al. 2002).

In Ethiopia, numerous epidemiological surveys of STHs were conducted and varying infection rates were reported from different regions and communities (Mengistu et al. 2007).Unsafe and inadequate provision of water, unhygienic living conditions and unsanitary waste management allow intestinal parasites and other communicable diseases to flourish in various localities (Habtamu and Kloos, 2006).Because of this and other reasons also in Ethiopia parasitic helminthic infections are the second most predominant causes of outpatient morbidity in the country.

According to Deribe et al. 2012 report, Ethiopia stands out for having the largest number of Neglected Tropical diseases (NTD) cases following Nigeria and the Democratic Republic of Congo. Ethiopia is estimated to have the second highest burden in terms of ascariasis, and the third highest burden of hookworm. Infection like trichuriasis is also common. A third of Ethiopians are infected with ascariasis, one quarter is 
infected with trichuriasis and one in eight Ethiopians lives with hookworm.

STH infections have not been targeted for control in Ethiopia (Tadese et al. 2008), though mass de-worming as a component of the Enhanced Outreach Strategy (EOS) targeting under five children started in 2004 (FMoH, 2004). Low-cost, high-coverage delivery of anti-helminthic treatment has been achieved in some settings (Montresor et al. 2007) but improving sanitation is more complex. In Ethiopia, for example, levels of access to improved sanitation in rural areas are very low (5.4\%) making evaluation of other components of intervention important (CSA and ORC Macro, 2006). Thus, this paper aimed to assesses current status of STH infection, controlling activities and progress of the disease in Ethiopia.

\section{Review}

\subsection{Burden of Soil-Transmitted Helminth Infection}

\subsubsection{Ascariasis}

Ascariasis is cosmopolitan and its distribution is largely determined by local habits in the disposal of faeces, because its eggs reach the soil in human faeces and so contaminate the human environment (Kightlinger et al. 1998). The parasite is one of the major public health problems in communities where the prevailing social environment is characterized by poverty, poor housing, inadequate sanitary practices and overcrowding (Chan, 1997 and Chan et al. 1994).

The worldwide prevalence of ascariasis is estimated to be more than 1.3 billion, approximately one quarter of the world population (Crompton, 1999), and over 250 million suffer from associated morbidity. It is estimated that 204 million cases of ascariasis occur in East Asia and the Pacific, 140 million in India, 97 million in South Asia, 84 million in Latin America and the Caribbean, 23 million in the Middle East and North Africa and 173 million in sub-Saharan Africa (De Silva et al. 2003). Ethiopia has the second highest burden rank of ascariasis in sub-Saharan Africa: 26 million people are infected, which covers $15 \%$ of the overall burden in subSaharan Africa (Hotez and Kamath, 2009).

Ascariasis found among literally all segments of the Ethiopian society. Of all the parasitic illnesses infecting adults and children in Ethiopia this is probably the most common parasitic disease, particularly in the malaria-free highlands (Belete and Kloos, 2006).

The prevalence among school aged children in different areas of Ethiopia was recorded at 39.8\% in North Gondar (Mathewos et al. 2014), 28.9\% in South Gondar (Jemaneh, 2000), 83.4\% in Wendogenet (Erko and Medhin, 2003), 37.2\% in Bushillo village (Terefe et al. 2011), 39.5\% in Jimma town and the national prevalence is estimated at $37 \%$ (Tadesse et al. 2008). Indoor and outdoor biotic contamination of the living environment arising partly from improper disposal of human waste, and partly from the integration of the lives of humans and animals accounts for the epidemic nature of parasitic infection in the country.

\subsubsection{Trichuriasis}

Infection with $T$. trichiura (trichuriasis) is the third most common helminth infections of humans (Peters and Pasvol, 2005). The distribution of trichuriasis is worldwide, being most abundant in the warm moist regions of the world. It afflicts about 1 billion people throughout the world (Pearson, 2002). In Ethiopia there are 21 million people infected with this parasite, which accounts $13 \%$ of the disease burden in sub-Saharan Africa (Tadesse et al. 2008). It is spread via fecal-oral transmission and high prevalence occurs in areas with tropical weather and poor sanitation practices (Bethony et al. 2006). The parasite commonly occurs together with Ascaris lumbricoides and likewise mainly affects children.

Although there are very few studies in Ethiopia regarding trichuriasis, a recent literature review has shown that trichuriasis incidences tend to follow the same pattern of occurrence as ascariasis, including the altitudinal pattern. On the central and northern plateau, T. trichiura was found in more than $90 \%$ of 50 communities, with a mean prevalence of $49 \%$ (Belete and Kloos, 2006). Prevalence of trichuriasis among school age children reported at $86.4 \%$ in Wondogenet (Erko and Medhin, 2003), 9.5\% in South Gondar (Jemaneh, 2000) and 47.6\% in Jimma town (Serkadis D. et al. 2013). Infection results from the ingestion of eggs in contaminated soil. Transmission may occur through the medium of food or water or directly from the hands of individuals. Children may be heavily infected and constitute important reservoirs.

\subsubsection{Hookworms}

Hookworm infection in humans is caused by an infection with Necator americanus and Ancylostoma duodenale and is transmitted through contact with contaminated soil. It is one of the most common chronic infections, with an estimated 740 million cases in areas of rural poverty in the tropics and subtropics (De Silva et al. 2003). Hookworm infection is among the most important tropical diseases in humans. The use of disability-adjusted life years as a quantitative measure of the burden of disease reveals that this infection outranks African trypanosomiasis, dengue, chagas disease, schistosomiasis, and leprosy (Hotez et al. 2003).

Hookworms are amongst the most widespread of soiltransmitted intestinal helminth parasites (Chan et al. 1994). An estimated 1.2 billion people worldwide have been infected (Chan, 1997), mainly in the tropics and subtropics, with the foci predominantly in areas of rural poverty within Asia, sub-Saharan Africa, and Latin America (De Silva et al. 2003). The greatest number of hookworm cases occurs in Asia, followed by sub-Saharan Africa.

In Ethiopia it is estimated that there are 11 million people infected with hookworm. Which makes the country to have the third highest burden rank in sub-Saharan Africa (Tadesse et al. 2008). According to the study conducted in different areas of Ethiopia the prevalence of hookworm among school age children was $22 \%$ in Northwestern Ethiopia (Hailu and Yimer, 2014), 28.4\% in southern Ethiopia (Terefe et al. 2011), $6.7 \%$ in eastern Ethiopia (Girum, 2005) and 4.9\% in northern 
Ethiopia (Mathewos et al. 2014).The national prevalence of hookworm is now estimated at $16 \%$ (Tadesse et al. 2008).

Necator americanus is more common than Ancylostoma duodenale in the country, and hookworm infections are most prevalent in communities located between 800 and $1200 \mathrm{~m}$ altitude. Infection rates ranged between $7 \%$ and $67 \%$ among 10 school populations in the lowlands of Gondar Region and at community level rates ranged from $4 \%$ to $75 \%$ among 16 villages in west Abaya (Park, 2004). In most areas, older children have the greatest incidence and intensity of hookworm infection. In rural areas where fields are fertilized with night soil, older working adults may also be heavily infected.

Table 1. Prevalence of STH infections in several areas of Ethiopia.

\begin{tabular}{llllll}
\hline \multirow{2}{*}{ Area } & \multirow{2}{*}{ Year } & Prevalence (\%) & & Hookworm & References \\
\cline { 3 - 5 } & & Ascaris & Trichuris & Mathewos et al. 2014 \\
North Gondar & 2012 & 39.8 & 6.1 & 4.9 & Erko and Medhin, 2003 \\
Wendogenet & 1999 and 2002 & 83.4 & 86.4 & - & Jemaneh, 2000 \\
South Gondar & 2000 & 28.9 & 9.5 & 12.9 & Serkadis et al. 2013 \\
Jimma Town & $2011-2012$ & 39.5 & 47.6 & 12.9 & Hailu and Yimer, 2014 \\
Northwestern Ethiopia & $2012-2013$. & 0.7 & - & 22 & Alemu et al. 2011 \\
Zarima town & 2009 & 22 & 2.5 & 19 & Terefe et al. 2011 \\
Bushulo village & 2007 & 37.2 & 41.5 & 28.4 & Legesse and Eriko, 2004 \\
South eastern Ethiopia & 2003 & 6.2 & 14.7 & 60.2 & Abossie and Seid, 2014 \\
Chencha town & 2012 & 60.5 & 9.7 & 2.2 & Mengistu et al. 2014 \\
Lumame town & $2011-2012$ & 26.2 & 1.7 & 7.7 & Kidane et al. 2014 \\
Wukro town & $2011-2012$ & 5.7 & 3.1 & 3.9 & \\
\hline
\end{tabular}

\subsection{Risk Factors Associated with Soil-Transmitted Helminth Infection}

\subsubsection{Behavior, Household Clustering, and Occupation}

Specific occupations and behaviors influence the prevalence and intensity of soil-transmitted helminth infections. Because of the high rates of hookworm infection among adults, occupation probably has a greater influence on hookworm epidemiology. Engagement in agricultural pursuits remains a common denominator for human hookworm infection (Hotez, 2002).

\subsubsection{Poverty, Sanitation, and Urbanization}

Soil-transmitted helminths depend for transmission on environments contaminated with egg-carrying feces. Consequently, helminths are intimately associated with poverty, poor sanitation, and lack of clean water. The provision of safe water and improved sanitation are essential for the control of helminth infection. Although the STH infections are neglected diseases that occur predominantly in rural areas, the social and environmental conditions in many unplanned slums and squatter settlements of developing countries are ideal for the persistence of A. lumbricoides (Crompton and Savioli, 1993).

Ascaris and Trichuris commonly occur both in urban environments, especially urban slums, and in rural areas. In some instances the prevalence of Ascaris infection is actually greater in urban environments (Phiri et al. 2000). In contrast, high rates of hookworm infection are typically restricted to areas where rural poverty predominates (Albonico et al. 1997). The urban-rural dichotomy between Ascaris-Trichuris versus hookworm can be partly understood by fundamental differences in the life cycles of these soil-transmitted helminths. The infective stages of Ascaris-Trichuris are embryonated eggs having enormous capacity for withstanding the environmental extremes of urban environments. Contained within the inner layer of Ascaris eggs is an unsaponifiable lipid known as ascaroside, which confers many of its hardy properties. In addition to ascaroside, Ascaris eggs are coated with a mucopolysacccharide that renders them adhesive to a wide variety of environmental surfaces; this feature accounts for their adhesiveness to everything from door handles, dust, fruits and vegetables, paper money and coins, etc (Kagei, 1983). Transmission through the ingestion of Ascaris eggs adhering to vegetables is a major route of transmission (Raisanen, 1985).

The social and environmental conditions in the unplanned slums of developing countries are ideal for the persistence of A. lumbricoides and T. trichiura. Many surveys have shown a high prevalence of these infections in children of slums, shanty towns and squatter settlements (Crompton and Savioli, 1993). However, the population density in urban slums should facilitate drug delivery and opportunities for health education. Individuals should also have easier access to purchasing anthelminthic drugs for treatment of their families (Crompton, 2001).

\subsubsection{Climate, Water, and Season}

Adequate warmth and moisture are key features for each of the soil-transmitted helminths. Ascaris and Trichuris eggs are hardier than hookworm L3 and therefore survive drier climates better. However, even for Ascaris and Trichuris, the rates of infection are low in arid climates. At low humidity (atmospheric saturation less than 80\%), human Ascaris ova do not embryonate; there appears to be no upper lethal limit on relative humidity (Brooker and Michael, 2000). For hookworm, moisture is especially critical. The infective third-stage larvae (L3) migrate along films of moisture. The presence of moisture will therefore allow L3 to travel vertically in the soil, particularly at night.

Since the presence of vegetation tends to prevent evaporation and conserve soil moisture, this feature has been 
used as a useful proxy measure of soil moisture (Hotez, 1995). It has been suggested that total rainfall in an area and its seasonal distribution may also help explain observed patterns of infection: wetter areas are usually associated with increased transmission of all three major soil transmitted helminth infections (Brooker and Michael, 2000). A study of the prevalence of helminth infections along the coastal plains of South Africa found transmission of A. lumbricoides to correlate with variables based on annual data, particularly rainfall and temperature (Appleton et al. 1999). Studies from West Africa suggest that a minimum of $1400 \mathrm{~mm}$ annual rainfall is necessary for the prevalence of $A$. lumbricoides to exceed 10\% (Brooker and Michael, 2000).

\subsection{Impact of Soil-Transmitted Helminths in Human Health}

STHs are one of the world's most important causes of physical and intellectual growth retardation (Hotez et al. 2006). The principal public health significance of STH infections lies in their chronic effects on health and nutrition. In addition to interference's in digestion and absorption of foods, Ascaris lumbricoides has been observed to decrease micro-nutrients and vitamin A absorption, probably by causing a structural abnormality of the mucosa in the small intestine ((Bundy et al. 1995). A. lumbricoides have been shown to play a significant role in childhood malnutrition, which leads to growth retardation, cognitive impairment, and poor academic performance, resulting in a poorer quality of life and less ability to contribute to society (Drake et al. 2000).

Hookworm infection is a recognized major contributor to gastrointestinal blood loss, iron and energy deficiencies, protein and zinc deficiencies and these thereby causing malnutrition and anemia which are most profound in women at childbearing age. Some 44 million pregnancies are currently complicated by maternal hookworm infections, placing both mothers and children at higher risk of death during pregnancy and delivery (Bundy et al. 1995). In the same way, Trichuris trichiura is now established to be associated with blood loss, malnutrition, and immunological disturbances (Stephenson et al. 2000).

Helminths co-infection with HIV has an impact on health of HIV infected individuals. Helminth infection leads to significant stimulation of the host immune response as these infections are characterized by the production of eggs, excretory products, and secretions. Helminth-infected individuals display increased levels of eosinophilia, increased IgE levels, and a Th2 immune bias (Kassu et al. 2003). Immuno-regulation in response to helminth infection may suppress HIV-1-specific CD4+ and CD8+ proliferation and cytokine production which may compromise control of HIV1 replication (Brown et al. 2006). Immune activation may also result in increased cellular susceptibility to HIV-1 infection.

It was already well established that immune activation is a major enhancing factor for HIV-1 viral replication and hence plasma HIV-1 viral load (VL), and so pre-existing immune activation in the host. Since people infected with helminths are immune-activated, they will be more prone to infection with HIV-1, and that once infected, they may have higher VL, and will therefore transmit the virus more easily and the infection will progress faster. Due to their dominant Th2 response, they will not develop potent HIV-1-specific cellular immune responses, which will be detrimental for the progression of the disease and for responding to vaccination against HIV-1 (Bentwich et al. 1998).

\subsection{Prevention and Control Measures}

\subsubsection{Improved Sanitation}

Improved sanitation is aimed at controlling transmission by reducing soil and water contamination. Sanitation is the only definitive intervention to eliminate STH infections but should cover a high percentage of population to be effective (Hotez et al. 2006).

\subsubsection{Health Education}

Health education is aimed at reducing transmission and reinfection by encouraging healthy behaviors. For STH infections, the aim is to reduce contamination of soil and water by promoting the use of latrines and hygienic behavior. Without a change in defecation habits, periodic deworming cannot attain a stable reduction in transmission (Hotez et al. 2006).

Health education can be provided simply and economically and presents no contraindications or risks. With this perspective, it is reasonable to include this component in all helminth control programs (Hotez et al. 2006).

\subsubsection{Morbidity Control Through Deworming}

The safe, inexpensive and efficacious single-dose oral drugs are now considered the cornerstone for morbidity control of STH targeting school-aged children and other high-risk groups (WHO, 2003). It is aimed at reducing morbidity by decreasing the worm burden (Bethony et al. 2003). Nowadays, it is not restricted to the treatment of symptomatic soil-transmitted helminth infections; the drugs are now used also for large-scale morbidity reduction in endemic communities. The causal link between chronic infection and impaired childhood development is extrapolated from the recorded improvement in these features after deworming (Awasthi et al. 2000).

Regular treatment with benzimidazole anthelminthic drugs in school-age children reduces and maintains the worm burden below the threshold associated with disease (Savioli et al. 2002). The benefits of regular deworming in this age group include improvements in iron stores, growth and physical fitness, cognitive performance, and school attendance. In younger children, studies have shown improved nutritional indicators such as reduced wasting, malnutrition, and stunting, and improved appetite (Stoltzfus et al. 1997).

However, there are obstacles that diminish the effectiveness of periodic deworming such as: the low efficacy of single-dose mebendazole and albendazole for the 
treatment of hookworm and trichuriasis due to high rates of post treatment reinfection for STHs in areas of high endemicity and diminished efficacy with frequent and repeated use possibly because of anthelminthic resistance (Bethony et al. 2003). According to Quinnell et al. (1993), after community-wide treatment, rates of hookworm infection reach $80 \%$ of pretreatment rates within 30-36 months. A. lumbricoides infection reached $55 \%$ of pretreatment rates within 11 months and T. trichiura infection reached $44 \%$ of pretreatment rates within 17 months. Despite re-infection, however, regular treatment to reduce the worm burden consistently could prevent some of the sequelae associated with chronic infection.

The effectiveness of drugs also must be closely monitored, especially in areas where drug pressure is high. As well, deworming without improved water supplies and sanitation cannot be relied on sustainable reductions in parasite frequency or intensity of infection (Bethony et al. 2003). Such strategies could result in substantial reductions in the worldwide disease burden in the years to come.

\section{Conclusion}

Soil-transmitted helminths have a high prevalence rate globally, especially in those societies living in impoverished conditions. In Ethiopia also, the disease affects millions people as a result of several risk factors. Health education using Medias, morbidity control through deworming and improving sanitation are now taken as a measurement to control the transmission rate. Further studies should be done to understand current status of the infection and measurements should continue to achieve worm eradication mellinium goal.

\section{References}

[1] Albonico, M., Chwaya, H.M., Montresor, A., Stolfzfus, R.J., Tielsch, J.M., Alawi, K.S. and Savioli, L. (1997). Parasitic infections in Pemba Island schoolchildren. East African Medical Journal 74, 294-8.

[2] Alemu, A., Atnafu, A., Addis, Z., Shiferaw, Y., Teklu, T., Mathewos, B., Birhan, W., Gebretsadik,S. and Gelaw, B. (2011)Soil transmitted helminths and schistosoma mansoni infections among school children in zarima town, northwest Ethiopia. BMC Infectious Diseases 11,189

[3] Abossie, A. and Seid, M. (2014).Assessment of the prevalence of intestinal parasitosis and associated risk factors among primary school children in Chencha town, Southern Ethiopia. BMC Public Health 14, 166

[4] Appleton, C.C., Maurihungirire, M. and Gouws, E. (1999). The distribution of helminth infections along the coastal plain of KwaZulu-Natal province, South Africa. Annals of Tropical Medicine and Parasitology 93, 859 - 868

[5] Awasthi, S., Pande, V.K. and Fletcher, R.H. (2000). Effectiveness and cost effectiveness of albendazole in improving nutritional status of preschool children in urban slums. Indian Pediatrics 37, 19-29.
[6] Belete, H. and Kloos, H. (2006). Intestinal Parasitism. In: The Epidemiology and Ecology of Health and Disease in Ethiopia. (Yemane Berhane, Damen Hailemariam and Helmut Kloos., Eds). Shama Books. Addis Ababa.

[7] Bentwich, Z., Kalinkovich, A., Weisman, Z. and Grossman Z. (1998). Immune activation in the context of HIV infection. Clinical \& Experimental Immunology 111, 1-2.

[8] Bethony, J., Brooker, S., Albonico, M., Geiger, S.M., Loukas, A., Diemert, D. and Hotez, P.J. (2006). Soil-transmitted helminth infections: ascariasis, trichuriasis and hookworm. Lancet 367, 1521-1532.

[9] Bethony, J., Brooker, S., Albonico, M., Geiger, S.M., Loukas, A.L., Diemert, D. and Hotez, P.J. (2003). Soil transmitted helminth infections: ascariasis, trichuriasis and hookworm. Lancet 367, 1521-1532.

[10] Bethony, J., Chen, J. and Lin, S. (2002). Emerging patterns of hookworm infection: influence of aging on the intensity of Necator infection in Hainan Province, People's Republic of China. Clinical Infectious Disease 35, 1336-44.

[11] Brooker, S. and Michael, E. (2000). The Potential of Geographical Information Systems and Remote Sensing in the Epidemiology and Control of Human Helminth Infections. Advances in Parasitology .47, 245-87.

[12] Brooker, S., J. Bethony, and P. J. Hotez. 2004. Human Hookworm Infection in the 21 st Century. Advances in Parasitology 58, 197-288.

[13] Brown, M., Mawa, P.A., Kaleebu, P. and Elliott, A.M. (2006) Helminths and HIV infection: epidemiological observations on immunological hypotheses. Parasite Immunology 28, 613623.

[14] Bundy, D.A.P. and Guyatt, H.L. (1996). Schools for health: Focus on health, education and the school-age child. Parasitology Today 12, 1-16.

[15] Bundy, D.A.P., Chan, M.S. and Savioli, L. (1995) Hookworm infection in pregnancy. Transaction of the Royal Society of Tropical Medicine and Hygiene 89, 521-522.

[16] Central Statistical Agency and ORC Macro (2006).Ethiopian Demographic and Health Survey. Addis Ababa Ethiopia and Calverton, Maryland: USA.

[17] Chan, L., Bundy, D.A. and Kan, S.P. (1994). Aggregation and predisposition to Ascaris lumbricoides and Trichuris trichiura at the familial level. Transaction of the Royal Society of Tropical Medicine and Hygiene 88, 46-48.

[18] Chan, M.S. (1997). The global burden of intestinal nematode infections: fifty years on. Parasitology Today 13, 438-43.

[19] Crompton, D.W. (1999). "How Much Helminthiasis Is There in the World?" Journal of Parasitology 85, 397-403.

[20] Crompton, D.W. (2001). Ascaris and ascariasis. Advances in Parasitology 48, 285-375.

[21] Crompton, D.W. and Savioli, L. (1993). Intestinal parasitic infections and urbanization. Bull World Health Organ. 71, 1-7.

[22] Deribe, K., Meribo, K., Gebre, T., Hailu, A., Ali, A., Aseffa, A., and Davey, G. (2012). The burden of neglected tropical diseases in Ethiopia, and opportunities for integrated control and elimination Parasites \& Vectors 5, 240 
[23] De Silva, N. R., Brooker, S., Hotez, P. J., Montresor, A., Engles, D. and Savioli, L. (2003). Soil-Transmitted Helminth Infections: Updating the Global Picture. Trends in Parasitology 19, 547-51.

[24] Drake, L., Jukes, M., Sternberg, R.J. and Bundy, D.A.P. (2000). Geo-helminthiasis (Ascariasis, Trichuriasis and hookworm): cognitive and developmental impact. Seminars in Pediatric Infections Diseases. 11, 245- 251.

[25] Erko, B. and Medhin, G. (2003). Human helminthiasis in Wondo Genet, southern Ethiopia, with emphasis on geohelminthiasis. Ethiopian Medical Journal 41, 333-44.

[26] Federal Ministry of Health (FMoH): Guidelines for the Enhanced Outreach Strategy (EOS) for Child Survival Interventions (2004). Addis Ababa, Ethiopia.

[27] Girum, T. (2005). The prevalence of intestinal helminthic infections and associated risk factors among school children in Babile town, eastern Ethiopia. Ethiopian Journal of Health Development 19(2), 140-147]

[28] Habtamu, B. and Kloos, H.(2006): The Epidemiology and Ecology of Health and Diseases in Ethiopia In: Intestinal parasitism (ed. Berhane Y, Hailemariam D, Kloos H.), pp. 519. Shama Books, Addis Ababa, Ethiopia.

[29] Hailu, T. and Yimer, M. (2014).Prevalence of Schistosoma mansoni and geo-helminthic infections among patients examined at Workemeda Health Center, Northwest Ethiopia. Journal of Parasitology and Vector Biology 6(5), 75-79.

[30] Hotez, P.J. (2002). China's hookworms. China Quart.

[31] Hotez, P.J. and Pritchard, D.I. (1995). Hookworm infection. Scientific American 272, 68-74.

[32] Hotez, P.J., Bundy, D.A.P. ,Beegle, K., Brooker, S., Drake, L., De Silva, N., Montresor, A., Engels, D., Jukes, M., Chitsulo, L., Chow, J., Laxminarayan, R., Michaud, C., Bethony, J., Correa-Oliveira, R., Shuhua, X., Fenwick, A. and Savioli, L. (2006). Helminth Infections: Soil-transmitted helminth infections and schistosomiasis. Disease Control Priorities in Developing Countries, 467-482.

[33] Hotez, P.J., Zhan, B. and Bethony, J.M. (2003). Progress in the development of a recombinant vaccine for human hookworm disease: the Human Hookworm Vaccine Initiative. International Journal of Parasitology 33, 1245-58.

[34] Hotez, PJ. and Kamath, A. (2009). Neglected tropical diseases in sub-saharan Africa: review of their prevalence, distribution, and disease burden. PLoS Neglected Tropical Diseases 3(8), e412.

[35] Jemaneh, L. (2000). The epidemiology of Schistosoma mansoni and soil-transmitted helminths in elementary school children from the South Gondar Zone of the Amhara National Regional State, Ethiopia. Ethiopian Medical Journal 38, 10518.

[36] Kagei, N. (1983). Techniques for the measurements of environmental pollution by infective stage of soil-transmitted helminths In: Collected Papers on the Control of SoilTransmitted Helminthiasis (ed.Yokogawa, M., ), pp. 27-46. Asian Parasite Control Organization, Tokyo.

[37] Kassu, A., Tsegaye, A., Wolday, D., Petros, B. and Aklilu, M. (2003). Role of incidental and/or cured intestinal parasitic infections on profile of $\mathrm{CD} 4+$ and $\mathrm{CD} 8+\mathrm{T}$ cell subsets and activation status in HIV-1 infected and uninfected adult Ethiopians. Clinical \& Experimental Immunology 132, 113119.

[38] Kidane, E., Menkir, S., Kebede, A. and Desta, M. (2014). Prevalence of intestinal parasitic infections and their associations with anthropometric measurements of school children in selected primary schools, Wukro Town, Eastern Tigray, Ethiopia. International Journal of Current Microbiology and Applied Sciences 3(3), 11-29.

[39] Legesse, M. and Erko, E. (2004). Prevalence of intestinal parasites among schoolchildren in a rural area close to the southeast of Lake Langano, Ethiopia. Ethiopian Journal of Health Development 18, 116-120.

[40] Mathewos, B., Alemu, A., Woldeyohannes, D., Alemu, A. Addis, Z. Tiruneh, M., Aimero, M. and Kassu, A. (2014). Current status of soil transmitted helminths and Schistosoma mansoni infection among children in two primary schools in North Gondar, Northwest Ethiopia: a cross sectional study. BMC Research Notes 7, 88 .

[41] Mengistu, A., Gebre-Selassie, S. and Kassa, T. (2007). Prevalence of intestinal parasitic infections among urban dwellers in southwest Ethiopia. Ethiopian Journal of Health Development 21(1), 12-17.

[42] Mengistu, W.,Melaku, W. and Tesfu, F. (2014). The prevalence of intestinal helminthic infections and associated risk factors among school children in Lumame town northwest Ethiopia. Journal of Parasitology and Vector Biology 6(10), 156-165.

[43] Montresor, A., Cong, DT., Le Anh, T., Ehrhardt, A., Montadori, E., Thi, TD., Le Kanhh, T., Albonico, A. and Palmer, KL. (2007). Cost containment in a school deworming program targeting over 2.7 million children in Vietnam. Transaction of the Royal Society of Tropical Medicine and Hygiene 101, 461-9.

[44] Park, K. (2004). Text Book of Preventive and Social Medicine. 18th Ed. Bandarsidas Bhanot Publishers, Jabalpur, India.

[45] Peters, W. and Pasvol, G. (2005). Atlas of Tropical Medicine and Parasitology: 6th Edn. Mosby Elsevier, pp. 429.

[46] Phiri, K., Whitty, C.J., Graham, S.M. and Ssembatya-Lule, G. (2000). Urban/rural differences in prevalence and risk factors for intestinal helminth infection in southern Mali. Annals of Tropical Medicine and Parasitology 94, 381-7.

[47] Pullan, RL. and Brooker, SJ. (2012). The global limits and population at risk of soil-transmitted helminth infections in 2010. Parasite \& Vectors 5, 81.

[48] Quinnell, R.J., Slater, A.F., Tighe, P., Walsh, E.A., Keymer, A.E., Pritchard, D.I. (1993). Reinfection with hookworm after chemotherapy in Papua New Guinea. Parasitology 106, 379 85 .

[49] Raisanen, S., Ruuskanen, L. and Nyman, S. (1985). Epidemic ascariasis - evidence of transmission by imported vegetables. Scandinavian Journal of Primary Health Care 3, 189-191.

[50] Savioli, L., Stansfield, S. and Bundy, D.A. (2002) Schistosomiasis and soil-transmitted helminth infections: forging control efforts. Transaction of the Royal Society of Tropical Medicine and Hygiene 96, 577-79. 
[51] Serkadis, D., Amare, W., Nejat J. and Zeleke M. (2013).Soiltransmitted helminths and associated factors among schoolchildren in government and private primary school in Jimma town, southwest Ethiopia. Ethiopian Journal Health Science. 23(3), 237-244

[52] Stephenson, L.S., Holland, C.V. and Cooper, E.S. (2000). The public health significance of Trichuris trichiura. Parasitology 121(Suppl), S73-95.

[53] Stoll, N.R. (1999). This wormy world. Journal of Parasitology 85, 392-396.

[54] Stoltzfus, R.J., Dreyfuss, M.L., Chwaya, H.M. and Albonico, M. (1997). Hookworm control as a strategy to prevent iron deficiency. Nutrition Reviews 55, 223-32.
[55] Tadesse, Z., Hailemariam, A. and Kolaczinski ,JH. (2008): Potential for integrated control of neglected tropical diseases in Ethiopia.Transaction of the Royal Society of Tropical Medicine and Hygiene 102, 213-214.

[56] Terefe, A., Shimelis, T., Mengistu, M., Hailu, A. and Erko, B. (2011). Schistosomiasis mansoni and soil-transmitted helminthiasis in Bushulo village, southern Ethiopia. Ethiopian Journal of Health Development 25(1), 46-50

[57] World Health Organization (2003). Action against worms. PPC Newsletter. March, Issue 1, World Health Organization, Geneva. 